Virginia Commonwealth University vCU Scholars Compass

2008

\title{
Communication Skills Instruction Utilizing Interdisciplinary Peer Teachers: Program Development and Student Perceptions
}

Sharon K. Lanning

Virginia Commonwealth University, sklanning@vcu.edu

Sonya L. Ranson

Carilion Clinic

Rita M. Willett

Virginia Commonwealth University, rwillett@vcu.edu

Follow this and additional works at: http://scholarscompass.vcu.edu/peri_pubs

Part of the Periodontics and Periodontology Commons

Reprinted by permission of Journal of Dental Education, Volume 72, 2 (February 2008). Copyright 2008 by the American Dental Education Association.

\section{Downloaded from}

http://scholarscompass.vcu.edu/peri_pubs/4

This Article is brought to you for free and open access by the Dept. of Periodontics at VCU Scholars Compass. It has been accepted for inclusion in Periodontics Publications by an authorized administrator of VCU Scholars Compass. For more information, please contact libcompass@vcu.edu. 


\title{
Communication Skills Instruction Utilizing Interdisciplinary Peer Teachers: Program Development and Student Perceptions
}

\begin{abstract}
Sharon K. Lanning, D.D.S.; Sonya L. Ranson, Ph.D.; Rita M. Willett, M.D.
Abstract: Lack of curricular time, faculty time, and funding are potential limitations for communication skills training in dentistry. Interdisciplinary collaboration amongst health care faculties could address these limitations. This article describes the development, implementation, and student perceptions of a communication skills program in dentistry. The program has four components: Knowledge, Observation, Simulation, and Experience (KOSE) and spans over the second and third years of dental school. KOSE allows students to obtain knowledge of and observe effective communication skills and practice these skills in the simulated and nonsimulated environment. A key feature of KOSE is the utilization of fourth-year medical and dental students as peer teachers. Evaluation of KOSE was geared toward student perceptions. Cross-sectional data were gathered via written surveys from 143 learners (second- and third-year dental students) in 2006-07. Students perceived the ability to recognize effective communication, demonstrated awareness of their communication strengths and weaknesses, and reported that skills gained were transferable to actual patient care. Interdisciplinary collaboration was a feasible way to address the lack of resources in the development of a communications skills program, which was perceived to be worthwhile by learners.
\end{abstract}

Dr. Lanning is Assistant Professor, Department of Periodontics, Virginia Commonwealth University School of Dentistry; Dr. Ranson is currently Simulation Laboratory Manager, Carilion Clinic, Roanoke, VA and was formerly Assistant Professor, Department of Continuing Professional Development and Evaluation Studies, Virginia Commonwealth University School of Medicine; and Dr. Willett is Associate Professor, Department of Internal Medicine, Virginia Commonwealth University School of Medicine. Direct correspondence and requests for reprints to Dr. Sharon K. Lanning, 521 North $11^{\text {th }}$ Street, Richmond, VA 23298; 804-8287951 phone; 804-828-0657 fax; sklanning@vcu.edu.

This project was supported by Virginia Commonwealth University's A.D. Williams Student Research Fellowship and Center for Teaching Excellence Small Grant Project and the American Dental Association Education Foundation's Program to Stimulate Innovation in Dental Education.

Key words: communication skills, dentist-patient relations, program evaluation, dental school curriculum, competencies, peer teachers, behavioral science

Submitted for publication 5/8/07; accepted 11/2/07

$\mathrm{E}$ ffective clinician-patient communication enhances diagnostic efficiency, clinical and ethical decision making, clinical outcomes, utilization of services, and patient and clinician satisfaction, ${ }^{1-4}$ as well as decreasing patient anxiety. ${ }^{5}$ Patients who respect and are satisfied with their doctors are less likely to submit formal complaints and pursue malpractice litigation. ${ }^{6,7}$ Conversely, poor communication is the most common reason for dissatisfaction with care and can result in termination of the relationship. ${ }^{8}$

Although communication skills may be learned in a clinical setting by trial and error, a more formal approach to instruction is more efficient and enhances student confidence. ${ }^{9}$ Communication in health care is not a personality trait but rather a series of learned skills ${ }^{9}$ that can be taught, learned, and retained. ${ }^{10}$ Studies have shown enhancement of communication skills, patient satisfaction, time management, and patient assessment as a result of communication skills training. ${ }^{10,11}$

The Accreditation Standards for Dental Education Programs include competencies in interpersonal and communications skills. ${ }^{12}$ Yet, in 2002, Yoshida et al. ${ }^{13}$ reported that, of forty U.S. and Canadian dental schools, only fourteen had courses specifically focusing on communication skills. Lectures were the most common teaching method, and written examinations were more frequently used for assessments. Three schools had interdisciplinary courses with schools of medicine, and eight schools did not formally teach communication skills. Hence, dental schools may be 
falling short of accreditation guidelines and the needs of the students and patients they serve.

Lack of curricular time, faculty time, and funding are potential limitations for communication skills training in dentistry. In particular, observation and feedback on students' communication skills are time-intensive. Simulated patient exercises and peer teaching have the potential to be both effective and efficient strategies. Simulated patients are a feasible and effective method of teaching and assessing communication skills in the health care setting. ${ }^{14-18}$ Peer teaching has potential advantages beyond its use in addressing the dental school faculty shortage. Bibb and Lefever reported that peer teaching programs may encourage dental students to consider careers in academic dentistry and foster greater enthusiasm for subject matter gained by both student instructors and their learners. ${ }^{19}$ Other benefits of peer teaching programs, such as greater teamwork, confidence, and respect for peers, are vital in developing professionalism. ${ }^{20-24}$

Faculty members at Virginia Commonwealth University School of Dentistry (VCU SOD) noted that the curriculum had limited opportunities for formal instruction on communication skills, assessment of skills, or performance feedback. Based on anecdotal evidence, students had difficulty organizing the dental interview, obtaining accurate information from patients, and determining patients' perspectives on their oral health care. VCU SOD lacked key resources for program development; there was limited faculty expertise in teaching communication skills, limited faculty time, and minimal funding. To address these issues, VCU SOD faculty consulted with VCU School of Medicine (SOM) faculty who had experience designing and implementing a communication skills program. Based on the clinical education literature and the resources available at VCU SOD, a communications skills program was developed.

This article describes the development and implementation of an instructional program for dental communication skills and student perceptions of the program.

\section{Program Development}

The goal of the VCU SOD communication skills program is to teach effective clinician-patient communication, defined as the exchange of information through verbal and nonverbal means that result in strong patient involvement, adherence to planned treatment, and patient and clinician satisfaction. ${ }^{25}$ The development of the program was guided by the Accreditation Standards for Dental Education Programs, ${ }^{12}$ medical and dental education literature, ${ }^{18,26-29}$ and Miller's framework for clinical competency. ${ }^{29,30}$ Miller's framework, based on Bloom's Taxonomy of Educational Objectives, ${ }^{31}$ describes a hierarchy of abilities needed to reach clinical competency. These abilities are increasingly complex, from knowledge at the most basic level to performance-based skills at higher levels. Miller's framework consists of knowledge (the student knows), competency (the student knows how), performance (the student shows how), and action (the student does). The framework distinguishes abilities in the simulated environment (competency and performance) versus authentic clinical situations (action). That is, measures of performance in the simulated environment alone may not predict performance in the authentic clinical environment, which must also be assessed.

Based on Miller's framework, the VCU SOD communication skills program was structured with four components: 1) Knowledge, 2) Observation, 3) Simulation, and 4) Experience (KOSE). In KOSE, students acquire knowledge about effective clinicianpatient communication, observe faculty demonstration of skills, practice in a simulated environment, and then hone their communication skills through real patient experiences. The Knowledge, Observation, and Simulation components occur in the second year of dental school, and Experience occurs during third-year clinical work.

The goal of the KOSE program is the development of effective clinician-patient communication skills. The program teaches these skills in the context of caring for patients with periodontal disease, for whom patient motivation and commitment to treatment are critical. Patients must be educated about the chronic nature of the disease, the causative and contributing factors, the treatment options, and the importance of self-care. The KOSE program was designed to teach communication in the context of a narrow content area so that students could focus on developing their communication skills. The program was designed so that communication skills gained from managing periodontal patients could be applied in other clinical situations. The first three components of the KOSE program were developed as modifications to existing second-year dental school courses of Periodontics (Knowledge and Observation) and Clinical Skills (Simulation). The fourth component of the KOSE program (Experience) is direct patient 
interaction in dental school-based and community clinics throughout the third year of dental school. The program was initiated in 2004-05 for the graduating class of 2007. Refinements were made based on that experience for 2005-06 (class of 2008). The program was implemented again in 2006-07 (class of 2009), when program evaluation was initiated.

\section{Program Description}

A detailed description of each component of the KOSE program follows. Figure 1 offers a brief overview of each component of the KOSE program and outlines student participants.

Knowledge. A one-hour lecture given by a dental faculty member to second-year dental students (D2s) describes effective clinician-patient communication. Students are taught fundamental techniques for the process of clinical communication, such as avoiding the use of medical and dental jargon, using concise language, and responding to a patient's concerns. Students are also taught the content of clinical communication, including diagnosis, etiology, and treatment options.

Observation. This one-hour interactive teaching session for D2s includes both observation and practice. First, a scripted role-play by two dental faculty members demonstrates less effective clinical communication skills. See Table 1 for examples of dialogue. During the role-play, students use checklists to identify the communication skills that they observe. Students discuss their observations and offer suggestions for improvement. A second scripted role-play demonstrates more effective communication skills.

For the last twenty minutes of the session, students practice role-playing with classmates. The D2s work in groups of three, with one student portraying a patient, one student role-playing the clinician, and one student observing the encounter. A brief case description including patient demographics; chief complaint; medical, dental, and social histories; periodontal diagnosis; etiology; and treatment options is provided. Student groups work independently and are not required to demonstrate their skills in front of the class. The two dental school faculty members monitor the groups and offer feedback where appropriate.

Simulation. A one-hour simulated clinic session engages small groups of D2s in role-playing exercises with paired fourth-year medical student (M4) and fourth-year dental student (D4) co-instruc- tors. The simulation takes place in the dental school clinic. Three D2s each have an opportunity to roleplay the clinician with a simulated patient portrayed by the M4. For each role-play, the other two D2s and the D4 observe the clinician-patient interaction, using checklists to assess the communication skills. Following the role-play, the student-clinician completes a self-assessment. Feedback after the role-plays is given by all members of the group in an interactive format facilitated by the M4 and D4. Checklists that were completed during each role-play help participants focus on specific skills. The discussion includes strengths and weaknesses for both the process of communication and the oral health content that was conveyed by the "clinician." Each role-play is fifteen minutes, and feedback is given in the last fifteen minutes of the session.

The role-plays depict three simulated patients, each with periodontal disease: 1) the anxious patient, 2) the inquisitive patient, and 3) the indifferent patient. For each case, the patient persona, patient demographics, chief complaint, medical, dental, and social histories, findings from clinical examination, periodontal diagnosis, etiology, and treatment options are outlined for the D2 and for the M4 and D4 co-instructors. In preparation for this simulated clinic, D2s have a twenty-minute orientation one to two weeks prior to the session. D2s are oriented to student roles and responsibilities. Patient cases are distributed at that time so that D2s can prepare for their individual role-play.

M4 and D4 students are carefully selected and trained as co-instructors for the simulated clinic experience. Both D4s and M4s are recruited from groups of students who have experience as teaching assistants. The D4s are experienced in teaching physical diagnosis and preclinical operative dentistry to D2s. The M4s are experienced in teaching clinical interviewing and physical diagnosis to first- and second-year medical students. Additionally, the M4s completed a fifty-five hour medical teaching elective. Since all D4 and M4 students involved in these teaching activities had been selected for their potential as teachers, a general call for peer communication instructors is put forth in these groups. Students are offered a modest financial incentive for their instruction and time spent in pre-session training.

Twelve M4 and D4 recruits attend a two-hour mandatory training session. Medical students are paired with dental students. Collegiality amongst the medical-dental student pairs is fostered by incorporating interactive activities into the training session. 


\section{Knowledge \\ Principles of effective clinician-patient communication presented to D2s<smiles>[CH]=C</smiles> \\ Observation \\ D2s observe effective clinician-patient communication as demonstrated by dental faculty role-play \\ D2s introduced to role-playing<smiles>C1=CC=C1</smiles>

\section{Simulation}

D2s practice effective clinician-patient communication by role-playing with M4 simulated patients Feedback facilitated by M4s and D4s<smiles>[CH]=C</smiles>

\section{Experience}

Matriculated D2s (D3s) apply learned communication skills as they manage authentic patients in dental school and community clinics

\section{D2s=second-year dental students D3s=third-year dental students $\mathrm{D} 4 \mathrm{~s}=$ fourth-year dental students M4s=fourth-year medical students}

Figure 1. Components of the KOSE program

The following topics are covered: 1) description of simulated session, including student roles and responsibilities; 2) guidelines for portraying the patient cases; and 3) facilitating feedback sessions. Guidelines for portraying the patient include the importance of staying in character. For each role- play, M4s are instructed to ask one question about diagnosis, etiology, and treatment options, to object to a treatment recommendation, and to offer one nonverbal clue of misunderstanding. D4s are directed to take attendance, give initial instructions to group members, distribute and collect checklists, and keep 


\section{Table 1. Excerpt dialogue from faculty role-play during Observation component}

Less Effective Clinician-Patient Communication

Patient, Mrs. Smith, is seated in dental chair.

Clinician standing adjacent to dental chair.

Clinician: "Today I am going to review your clinical findings from oral examination and radiographic survey. Additionally, I will tell you about your diagnosis, etiological factors, and treatment. Before I begin, do you have any immediate questions?"

Clinician immediately looks in patient's chart.

Clinician: "You also have to improve your oral hygiene."

Mrs. Smith: "But I brush my teeth three times a day and floss."

Clinician: "There are areas in your mouth that you are missing with your technique. You will have to work on that."

time. The co-instructors are taught to facilitate the feedback discussion, emphasizing communication strengths and identifying one or two weaknesses. The M4s are asked to focus on the verbal and nonverbal communication process, while D4s focus on the clinical oral health content. Co-instructors are asked to elicit ideas from the D2s on how to improve communication skills.

Experience. As VCU D2s matriculate into the third year of dental school, they have extensive contact with patients. Third-year dental students (D3s) treat patients in the school's clinics at least four days per week and provide comprehensive care to patients within their patient pool. These students also rotate through on-site specialty, hospital-based, and off-site community general practice clinics for approximately four to six weeks during their third year. These experiences provide numerous opportunities for D3s to interact with diverse groups of patients in various health care facilities and apply their communication skills to direct patient interactions. Students are informally observed while interacting with patients in the dental school and community clinics including, but not limited to, patient interviewing, motivation,
More Effective Clinician-Patient Communication

Patient, Mrs. Smith, is seated in dental chair.

Clinician is seated facing dental chair at eye level with patient.

Clinician: "Today we are going to accomplish 4 things: 1. review the information collected during your clinical exam, 2. discuss your diagnosis, 3 . discuss the cause of your gum problems, and 4. together determine treatment that is best for you. Before I begin, do you have any immediate questions?"

Clinician allows time for patient to respond and observes patient for nonverbal clues.

Clinician: "Since plaque and calculus begin to form very quickly after removal, I will teach you how to best care for your mouth through the use of proper brushing and flossing techniques so that you minimize the occurrence of these accumulations."

Mrs. Smith: "But I brush my teeth three times a day and floss."

Clinician: "Fantastic. Getting patients in the habit of brushing and flossing is the most difficult part. However, there are areas in your mouth that you are missing with your technique. I can help you become more effective." and obtaining informed consent. D3s may obtain feedback on their communication skills both verbally and in writing.

Resources Required. The KOSE communication skills program was designed to offer instruction, individual practice, and feedback to each student within the constraints of limited resources. The communication skills lecture required one dental faculty member, and the observation session required two. The simulated clinic session required six M4s and six D4s for peer instruction, one faculty member for oversight, and two staff members (ten hours total) for logistical support. Consultation for program development and evaluation was provided by two faculty members from the SOM. Curriculum time (prior to actual clinical experience) was limited to three hours per student: one hour for lecture, one hour for observation, and one hour for simulation. However, the observation was conducted twice, each session involving half the class. The simulated clinic required eight sessions, done in two four-hour blocks, to accommodate all students. Outside of faculty time, the program cost approximately $\$ 1,500$ to provide lunches and stipends to M4 and D4 peer teachers. 


\section{Program Evaluation Methods}

This project was approved by the university's Institutional Review Board, and consent was obtained from student subjects. Evaluation based on student perspective was obtained for the observation session and for the simulated clinic experience from D2s in 2006-07 (class of 2009). D4 and M4 student co-instructors completed a survey on their teaching experience. Student perspective on the entire communication program was obtained from students completing the D3 year in 2007 (class of 2008). This cross-sectional design provided an expedited evaluation of the KOSE program by capturing two dental school classes' perceptions at different points of communication skills development during one academic year.

The KOSE program evaluation addressed student perspectives on three questions:

1) Did students gain sufficient knowledge to recognize effective clinician-patient communication?

2) Did students gain an awareness of their strengths and weaknesses in communicating with patients?

3) Did students feel empowered to apply the principles of effective clinician-patient communication to real patient interactions?

Surveys were developed to assess these questions utilizing VCU SOD curriculum objectives and the Accreditation Standards for Dental Education Programs. ${ }^{12}$ For the majority of survey items, students were asked to rate their level of agreement using a five-point Likert scale that ranged from $1=$ strongly disagree to $5=$ strongly agree. Open-ended items invited narrative comments. Demographic information was included. Surveys were reviewed and revised by dental and medical school faculty with experience in teaching communication skills. The underlying assumption was that students would report that the communication skills exercises enhanced their learning and that the program would have a positive impact on the way they approached patients in the clinical environment.

Observation. Upon completion of the faculty role-playing exercise, a survey with six Likert scale items was administered to the D2s (Table 2). The survey analyzed their perceptions of the efficacy of faculty role-playing in preparing them to communicate with patients.
Simulation. D2s' perceptions of their ability to transfer the principles of effective clinician-patient communication skills to simulated clinical situations were assessed by using a survey with seven Likert scale items (Table 3). M4 and D4 student co-instructors were asked to respond to a survey with five Likert scale items about their teaching experience.

For the Observation and Simulation surveys, results were analyzed with descriptive statistics. Narrative comments were read by two reviewers who agreed on themes and tallied the frequency of the most common themes.

Experience. D3 perceptions about changes in their communication skills were gathered through post-training surveys using the retrospective pre- to post-test methodology. ${ }^{32,33}$ The retrospective pretest methodology was used in order to avoid a responseshift bias, which occurs when the educational intervention itself changes the learner's understanding of competence. Responses to a conventional pretest would be calibrated to a naïve standard of competence, and post-test responses would be based on a more informed (recalibrated) standard. Thus, use of the retrospective pre- to post-test methodology addresses the response shift bias.

After one year of real patient experience, D3s completed a survey with thirteen Likert scale items asking them to rate their communication skills before and after participation in the KOSE program. A variety of skills were assessed including the ability to recognize verbal and nonverbal cues, increase accuracy of history taking, motivate patients, and provide appropriate information (Table 4). Data were analyzed using a paired sample t-test and Cohen's $d$ measure of effect size.

\section{Results}

Second-year and third-year dental school classes were made up of ninety-four and eighty-one students, respectively. Ninety-five percent of the D2 class (eighty-nine out of ninety-four students) participated in the program evaluation. Of these eightynine participants, 78 percent were white, 63 percent were male, 82 percent were between ages twenty-one and thirty, and 88 percent reported English as the primary language. Sixty-six percent of students in the D3 class (fifty-four out of eighty-one students) participated in the program evaluation. Of these fiftyfour participants, 75 percent were white, 69 percent were male, 87 percent were between ages twenty-one 
Table 2. Frequency distribution of second-year dental students' rating of the Observation component $(n=89)$

\begin{tabular}{|c|c|c|c|}
\hline Questionnaire Items & $\begin{array}{l}\text { Agree } \\
\#(\%)\end{array}$ & $\begin{array}{l}\text { Neutral } \\
\#(\%)\end{array}$ & $\begin{array}{l}\text { Disagree } \\
\#(\%)\end{array}$ \\
\hline $\begin{array}{l}\text { Q1. The faculty role-playing exercise helped me distinguish between } \\
\text { less and more effective clinician-patient communication. }\end{array}$ & $86(97 \%)$ & $0(0)$ & $3(3 \%)$ \\
\hline $\begin{array}{l}\text { Q2. Assessing the clinician's role during the faculty role-playing } \\
\text { exercise enhanced my understanding of how to use the communication } \\
\text { checklists. }\end{array}$ & $83(95 \%)$ & $3(3 \%)$ & $2(2 \%)$ \\
\hline $\begin{array}{l}\text { Q3. The student role-playing exercise helped me become comfortable } \\
\text { with role-playing. }\end{array}$ & $45(51 \%)$ & $30(34 \%)$ & $12(15 \%)$ \\
\hline $\begin{array}{l}\text { Q4. I learned something during this exercise that I will use in future } \\
\text { interactions with patients. }\end{array}$ & $83(94 \%)$ & $4(5 \%)$ & $1(1 \%)$ \\
\hline Q5. The right amount of time was allotted for this exercise. & $67(75 \%)$ & $13(15 \%)$ & $9(10 \%)$ \\
\hline Q6. Overall, this session was worthwhile. & $83(93 \%)$ & $4(5 \%)$ & $2(2 \%)$ \\
\hline
\end{tabular}

Table 3. Frequency distribution of second-year dental students' rating of the Simulation component $(n=89)$

\begin{tabular}{|c|c|c|c|}
\hline Questionnaire Items & $\begin{array}{c}\text { Agree } \\
\#(\%)\end{array}$ & $\begin{array}{c}\text { Neutral } \\
\#(\%)\end{array}$ & $\begin{array}{c}\text { Disagree } \\
\#(\%)\end{array}$ \\
\hline Q1. Made me aware of my strengths in communicating with patients. & $82(92 \%)$ & $5(6 \%)$ & $2(2 \%)$ \\
\hline Q2. Made me aware of my weaknesses in communicating with patients. & $80(90 \%)$ & $6(7 \%)$ & $3(3 \%)$ \\
\hline Q3. I felt comfortable practicing communication skills in front of classmates. & $69(78 \%)$ & $15(17 \%)$ & $5(6 \%)$ \\
\hline Q4. This exercise improved my confidence in communicating with patients. & $70(79 \%)$ & $17(19 \%)$ & $2(2 \%)$ \\
\hline Q5. I learned something that I will use in future interactions with patients. & $84(94 \%)$ & $4(5 \%)$ & $1(1 \%)$ \\
\hline Q6. I would like to participate in this type of exercise again. & $72(81 \%)$ & $9(10 \%)$ & $8(9 \%)$ \\
\hline Q7. Overall, the experience was worthwhile. & $81(91 \%)$ & $5(6 \%)$ & $3(3 \%)$ \\
\hline
\end{tabular}

and thirty, and 93 percent reported English as the primary language.

Ninety-three percent of D2s indicated that observation of the faculty role-playing exercise was worthwhile (Table 2). While only 51 percent indicated that they felt more comfortable with role-playing, 97 percent agreed that they were better prepared to distinguish effective from non-effective communication and 94 percent reported learning skills that will help them in the future. In narrative comments, D2s commonly reported learning the importance of listening to patients' concerns ( 73 percent), reducing medical and dental jargon ( 68 percent), and being conscious of nonverbal cues (54 percent).

Most D2s (91 percent) felt the simulated clinic exercise was worthwhile (Table 3). Students were comfortable practicing communication skills in front of their group members (78 percent) and were willing to participate again ( 81 percent). When asked what they learned from the exercise, D2s frequently responded with 1) importance of verifying patients' understanding of planned treatment by asking openended questions (80 percent); 2) use of appropriate language (78 percent); 3 ) avoidance of medical/dental jargon (72 percent); 4) maintenance of eye contact (66 percent); 5) importance of developing rapport with patients (60 percent); 6) paying attention to patients' nonverbal cues (57 percent); 7) importance of demonstrating empathy (54 percent); 8) structuring an interview/meeting with a patient (40 percent); and 9) diagrams/pictures enhance explanation of disease state (32 percent). D2s expressed a need for more time in each activity ( 20 percent), a shorter rating checklist ( 8 percent), and more time to practice these skills after the session ( 6 percent). In addition, D2s agreed that the dental (93 percent) and medical student (91 percent) instructors helped them develop their communication skills.

All M4s and D4s provided positive feedback on the simulated clinic sessions. Both groups agreed (M4s [94 percent] and D4s [90 percent]) that the training session adequately prepared them for the 


\begin{tabular}{|c|c|c|c|c|}
\hline Questionnaire Items ( $1=$ very low, $5=$ very high) & $\begin{array}{c}\text { Before KOSE } \\
\text { Mean (SD) }\end{array}$ & $\begin{array}{l}\text { After KOSE } \\
\text { Mean (SD) }\end{array}$ & $t$ value* & Cohen's $d$ \\
\hline Q1. Provide structure to discussions with patients. & $3.41(.768)$ & $4.08(.675)$ & $-5.53^{*}$ & .94 \\
\hline Q2. Build rapport with patients. & $3.70(.799)$ & $4.09(.741)$ & $-3.18^{*}$ & .56 \\
\hline Q3. Recognize patients' verbal cues. & $3.38(.860)$ & $3.98(.665)$ & $-4.07^{*}$ & .78 \\
\hline Q4. Recognize patients' nonverbal cues. & $3.36(.811)$ & $4.02(.747)$ & $-4.72^{*}$ & .85 \\
\hline Q5. Decrease patient anxiety. & $3.45(.889)$ & $4.08(.730)$ & $-4.70^{*}$ & .87 \\
\hline Q6. Increase accuracy of history taking. & $3.32(.754)$ & $3.83(.753)$ & $-3.98^{*}$ & .68 \\
\hline Q7. Decrease time of history taking. & $3.34(.732)$ & $3.75(.757)$ & $-3.33^{*}$ & .96 \\
\hline Q8. Provide appropriate type and amount of information to patients. & $3.26(.788)$ & $3.94(.770)$ & $-4.70^{*}$ & .87 \\
\hline Q9. Explore patients' perspectives relative to treatment preferences. & $3.40(.743)$ & $4.04(.759)$ & $-4.75^{*}$ & .91 \\
\hline Q10. Negotiate a mutually acceptable treatment plan. & $3.42(.795)$ & $4.04(.706)$ & $-4.43^{*}$ & .91 \\
\hline Q11. Motivate patients. & $3.47(.749)$ & $4.02(.820)$ & $-4.10^{*}$ & .94 \\
\hline Q12. Relate to patients' concerns and desires. & $3.58(.819)$ & $4.19(.681)$ & $-4.85^{*}$ & .92 \\
\hline Q13. Manage patients' concerns regarding undesirable outcome. & $3.38(.790)$ & $4.00(.784)$ & $-4.70^{*}$ & .90 \\
\hline
\end{tabular}

${ }^{*} \mathrm{p}<.001$

simulated exercises. A high percentage of M4s and D4s also agreed with the following survey items: 1 ) I was comfortable assessing D2s (89 percent); 2) I would encourage other M4/D4 students to participate in this activity next year (88 percent); and 3) D2s were prepared for and engaged in the exercise ( 82 percent). Ninety-two percent of M4s agreed that they were comfortable playing a simulated patient. M4s and D4s reported that more time should be allotted for each session (22 percent) and that the checklist was too complicated ( 6 percent). They also felt that the addition of charts or radiographs to the cases might enhance the activity ( 24 percent).

After completing the entire KOSE program, including one year of direct work with patients, D3s reported improvements in specific communication skills ( $X=3.75$ to 4.09 ) (Table 4$)$. These shifts from pre- to post-values were seen in all areas with $t$-values that ranged from -3.18 to $-5.53(p<.001)$. In addition, the Cohen's $d$ values indicated moderate to high practical significance ( $d=.56$ to .96$)$. Of the skills that reached moderate to high practical significance, up to 48 percent of students rated an improvement in skills by one using the five-point Likert scale, and up to 11 percent of students rated an improvement by two or more.

\section{Discussion}

The VCU SOD aimed to develop a program to enhance student communication skills. The KOSE program is consistent with Miller's framework, allowing students to gain knowledge through lecture presentation and observation and then to practice skills in the simulated and authentic clinical environments. The KOSE program utilizes small-group experience, performance-based instruction, simulated patients, skills assessment, and feedback, which are all strategies recommended for communication skills training. ${ }^{18,27}$ Program evaluation was based largely on student perceptions. Importantly, D3s who had a year of clinical experience described improvement in each of the specified communication skills.

This VCU SOD communications skills program is notable for its success despite limited faculty time, limited curriculum time, and limited financial resources. Collaboration with faculty in the SOM aided program development. Senior medical and dental students provided the patient simulation, communication skills assessment, and feedback necessary for the small-group simulated clinic experience.

Program evaluation focused on students' recognition of effective clinician-patient communication, 
awareness of their own strengths and weaknesses as communicators, and application of learned skills to real patient interactions. D2s reported that the Observation and Simulation components of the program were beneficial, enhanced their ability to distinguish between more and less effective communication, and made them aware of their strengths and weaknesses as communicators in the health care setting. D3s perceived that their skills enhanced from before to after participation in the program. Students reported that they learned how to listen to patients' concerns, build rapport with patients, reduce medical and dental jargon, negotiate a mutually acceptable treatment plan, and recognize patients' nonverbal cues. Overall, students perceived the communication skills development program to be worthwhile and a useful part of their educational experience.

Most of the peer instructors found the experience valuable enough to recommend it to others. Fourth-year dental students commented that they learned communication skills that they would use in future practice. Medical students reported that they learned something new about dentistry and about oral health. These findings are consistent with research demonstrating that peer teaching positively affects the learner and instructor by reinforcing concepts and enhancing motivation for learning. ${ }^{19}$ Peer teaching has the potential to help address the dental school faculty shortage ${ }^{34}$ and foster interest in dental education. This program is notable for utilizing peer instruction across disciplines, with potential benefits of building respect and collegiality between professions and enhancing student understanding of the scope of practice and the importance of collaboration in the comprehensive management of patients.

Interdisciplinary course planning amongst health sciences faculty offers opportunities for resource sharing, collaborative relationships, and professional development. Building relationships with faculty members outside of dental schools may provide teaching materials and human resources needed to enhance the delivery of dental education. These relationships may also support professional development since they expose health sciences faculty members to new teaching methodologies and content knowledge. Furthermore, collaborative relationships amongst faculty may enhance job satisfaction and faculty retention. ${ }^{35,36}$ The importance of multidisciplinary collaboration has been supported on a national level as explained in the 2003 Report on Academic Health Centers, which strongly endorses the integrated development of educational curricula and approaches to teaching health professionals. ${ }^{37}$

There are several limitations in the evaluation of this educational innovation. The evaluation was based on student perspectives at one academic institution. Measures of actual student performance could provide better measures of the program's effects on knowledge and skills. Objective measurement could include pre- and post-knowledge testing of communication protocol, accuracy of gathered information during patient interviewing, and patient retention rates. In this study, student perspective was gathered in a cross-sectional rather than longitudinal manner. However, the student demographics and the instructional program were similar for the two groups of students. Evaluation of the D3s' perceived change in communication skills used the retrospective pretest methodology in order to avoid a response-shift bias. Potential limitations of this methodology are systematic cognitive biases due to a tendency to believe that the present self is better than the past self or due to an attempt to justify the effort expended with the belief that change must have occurred. ${ }^{32,33}$ Although the KOSE program's practical significance is difficult to quantify, 78 percent of D3s perceived an improvement in at least one specific communication skill. Skills such as recognizing patient nonverbal clues, exploring patient perspective relative to treatment preferences, and negotiating a mutually acceptable treatment plan were skills perceived to be enhanced. These skills are worth noting since they correspond to the fundamental definition of effective communication that was an integral part of program development.

There are several potential limitations to this learning experience. The skills of the M4s as simulated patients are unknown. Professional simulated patients (usually laypersons) go through extensive training and may differ in their portrayal of patients and their feedback. Although these medical students were not familiar with the dental aspects of the patient cases, they have more medical training than typical simulated patients, which might affect their role-play and feedback. The completeness and consistency of feedback given to D2s were not evaluated in this study. The teaching and clinical experience of the peer instructors, their level of training prior to the simulated session, and the short amount of time devoted to feedback may have affected the feedback given. This program gave students only one simulated practice opportunity using a narrow spectrum of the dental content and psychological issues facing practicing dentists. Multiple opportunities for observed 
practice with feedback may be required for students to learn and retain communication skills needed to manage the full scope of dental practice and the varied psychological, ethical, and cultural issues.

The KOSE program, utilizing interdisciplinary peer teachers for a simulated clinic experience, has been a successful approach to communication skills training in a dental school with limited resources for this aspect of the curriculum. Further development of the KOSE communication skills program will include more curricular hours incorporating a greater variety of dental scenarios. Additional outcomes data will include faculty ratings of M4s and D4s as simulated patients and peer instructors. This will help determine the authenticity of mock patients and the quality of performance-based feedback provided to D2s by their peer instructors. Modifications to the KOSE program will continue based on these findings and on further evaluation of students' perceptions and performance.

\section{Acknowledgments}

The authors would like to thank Drs. Aaric Allred, Benjamin Crowley, Ryan Edmunds, and John Gunsolley and Mr. Jonathon Gorman for assistance with data analysis. This project was supported by Virginia Commonwealth University's A.D. Williams Student Research Fellowship and Center for Teaching Excellence Small Grant Project and the American Dental Association Education Foundation's Program to Stimulate Innovation in Dental Education.

\section{REFERENCES}

1. Evans BJ, Stanley RO, Mestrovic R, Rose L. Effects of communication skills training on students' diagnostic efficiency. Med Educ 1991;25(6):517-26.

2. Irwin RS, Richardson ND. Patient-focused care: using the right tolls. Chest 2006;130(1):73S-82S.

3. Kulich KR, Beggren U, Hallberg LR. Model of the dentistpatient consultation in a clinic specializing in the treatment of dental phobic patients: a qualitative study. Acta Odontol Scand 2000;58:63-71.

4. Brattstrom V, Ingelsson M, Aberg E. Treatment cooperation in orthodontic patients. Br J Orthod 1991;18:37-42.

5. van der Molen HT, Klaver AA, Duyx MP. Effectiveness of a communication skills training programme for the management of dental anxiety. Br Dent J 2004;196(2):101-7.

6. Huntington B, Kuhn N. Communication gaffes: a root cause of malpractice claims. BUMC Proceedings 2003;16:157-61.

7. Mellor AC, Milgrom P. Dentists' attitudes towards frustrating patients' visits: relationship to satisfaction and malpractice complaints. J Public Health Dent 1996;56:6-11.
8. Hall JA, Roter DL, Katz NR. Meta-analysis of corrections of provider behavior in medical encounters. Med Care 1988;26:657-75.

9. Kurtz S, Silverman J, Draper J. Teaching and learning communication skills in medicine. $2^{\text {nd }}$ ed. Oxon, CA: Radcliffe Publishing Co., 2005.

10. Oh J, Segal R, Gordaon J, Boal J, Jotkowitz A. Retention and use of patient-centered interviewing skills after intensive training. Acad Med 2003;76:647-50.

11. Duff FD. Dialogue: the core clinical skill. Ann Intern Med 2004;128:139-41.

12. Commission on Dental Accreditation. Accreditation standards for dental education programs. Chicago: Commission on Dental Accreditation, American Dental Association, 1998.

13. Yoshida T, Milgrom P, Coldwell S. How do U.S. and Canadian dental schools teach interpersonal communication skills? J Dent Educ 2002;66(11):1281-8.

14. Rees C, Sheard C, McPherson A. Medical students' view and experiences of methods of teaching and learning communication skills. Patient Educ Couns 2004;54(1): 119-21.

15. Frasier RC, McKinley RK, Mulholland H. Consultation competence in general practice: testing the reliability of the Leicester assessment package. Br J Gen Pract 1994;44:293-96.

16. Vu NV, Barrons H. Use of standardized patients in clinical assessments: recent developments and measurement findings. Educ Res 1994;23:23-30.

17. Binghamton L, Burrows P, Caird R, Holgrove G, Jackson N. Simulated surgery using standardized patients to assess clinical competence of GP registrars: a potential clinical competence of the MRCGP examination. Educ Gen Pract 1996;7:102-11.

18. Hannah A, Millichamp CJ, Ayers KMS. A communication skills course for undergraduate dental students. J Dent Educ 2004;68(9):970-7.

19. Bibb CA, Lefever KH. Mentoring future dental educators through an apprentice teaching experience. J Dent Educ 2002;66(6):703-9.

20. Brueckner JK, MacPherson BR. Benefits from peer teaching in the dental gross anatomy laboratory. Eur J Dent Educ 2004;8(2):72-7.

21. Krych AJ, March CN, Bryan RE, Peake BJ, Pawlina W, Carmichael SW. Reciprocal peer teaching: students teaching students in the gross anatomy laboratory. Clin Anat 2005;18(4):297-301.

22. Zanting A, Verloop N, Vermunt JD. Student teachers' beliefs about mentoring and learning to teach during teaching practice. Br J Educ Psychol 2001;71(1):57-80.

23. Owens LD, Walden DJ. Peer instruction in the learning laboratory: a strategy to decrease student anxiety. J Nurs Educ 2001;40(8):375-7.

24. Blower S, Ramsey P, Merriman C, Grooms J. Patterns of peer teaching in nursing. J Nurs Educ 2003;42(5): 204-11.

25. Skeff KM, Stratos GA, Berman J. Educational theory and teaching medical interviewing. In: Lipkin M, Putman SM, Lazare A, eds. The medical interview: clinical care, education, and research. New York: Springer-Verlag, 1995:379-87. 
26. Hottel TL, Hardigan PC. Improvement in the interpersonal communication skills of dental students. J Dent Educ 2005;69(2):281-4.

27. Putman SM, Stiles WB, Jacob MC, James SA. Teaching the medical interview: an intervention study. J Gen Intern Med 1988;3:38-47.

28. Maguire P, Fairburn S, Fletcher C. Consultation skills of young doctors: benefits of feedback training in interviewing as a students persist. BMJ 1986;292:1573-5.

29. Miller GE. The assessment of clinical skills/competence/ performance. Acad Med 1990;65(9):S63-S67.

30. Norcini JJ. Work-based assessment. BMJ 2003;326(5): $753-5$.

31. Bloom BS, Englehart MD, Furst EJ, Hill WH, Krathwohl DR. Taxonomy of educational objectives: the classification of educational goals. Handbook I: cognitive domain. New York: David McKay Co., 1956:12-5.
32. Hill LG, Betz DL. Revisiting the retrospective pretest. Am J Evaluation 2005;26(4):501-17.

33. Lam TCM, Bengo P. A comparison of three retrospective self-reporting methods of measuring change in instructional practice. Am J Evaluation 2003;24(1):65-80.

34. Weaver RG, Haden NK, Valachovic RW. Dental school vacant budgeted faculty positions, academic year 2002-03. J Dent Educ 2004;68(5):574-80.

35. Glickman GN, Gluskin AH, Johnson WT, Lin J. The crisis in endodontic education: current perspectives and strategies for change. J Endod 2005;31(4):255-61.

36. Schrubbe KF. Mentorship: a critical component for professional growth and academic success. J Dent Educ 2004;68(3):324-8.

37. Academic health centers: leading change in the $21^{\text {st }}$ century, 2003. At: www.iom.edu/fileasp?id=13779. Accessed October 15, 2005 